\title{
Trajetórias de acesso ao mundo da escrita: relevância das práticas não escolares de letramento para o letramento escolar
}

\author{
Angela B. Kleiman*
}

\section{Resumo}

Utilizando uma concepção sócio-histórica do letramento, que se opõe a uma concepção instrumental dos usos da escrita (STREET, 1984; KLEIMAN, 1995), este artigo discute aspectos do letramento escolar, apontando algumas implicaçóes dessa concepção para o ensino e a pesquisa. São apresentadas duas linhas de pesquisa desenvolvidas no grupo de pesquisa Letramento do Professor: a que tem por objetivo o desenvolvimento, análise e documentação de 'projetos de letramento' e seus efeitos no letramento escolar e a que focaliza práticas de letramento locais e seus impactos nas identidades de líderes e agentes comunitários. Ambas visam a contribuir para o desenvolvimento de programas de ensino favoráveis aos alunos socialmente mais vulneráveis, cujo acesso ao mundo da escrita encontra múltiplos obstáculos.

Palavras-chave: Projeto escolar. Cultura escrita.

* Professora Titular colaboradora voluntária na Universidade Estadual de Campinas. 


\section{Introdução}

Há quase uma década, o grupo de pesquisa Letramento do Professor desenvolve pesquisas com o objetivo de estudar e compreender os modos de inserção no mundo da escrita de grupos cujo processo de acesso aos bens culturais por meio da escolarização culmina, muitas vezes, no fracasso e na exclusão. Uma premissa importante desses trabalhos é a de que o processo de tornar-se letrado é um processo identitário, porque, em uma sociedade profundamente dividida por questôes sociais, como a brasileira, o processo de inserção na cultura da escrita equivale a um processo de aculturação, com a violência simbólica aí pressuposta. Assim como o processo de inclusão envolve questôes identitárias para os mais pobres, que provêm de famílias sem escolaridade, também o processo de exclusão pode ter consequências para a construçấo identitária de jovens e adolescentes que passaram, sem sucesso, pela escola.

A concepçáo identitária do letramento se opóe a uma concepçáo instrumental, funcional da escrita, que se centra geralmente nas capacidades individuais de uso da língua escrita em cotejo com uma norma universal do que é ser letrado. Para a perspectiva identitária, são de interesse tanto as trajetórias singulares de sujeitos que atuam como agentes de letramento em suas comunidades de origem quanto os esforços coletivos de inserção na cultura letrada por parte de determinados grupos que sáo movidos por finalidades políticas, econômicas, sociais ou culturais, geralmente em trajetórias coletivas ou individuais de luta e resistência.

Parece paradoxal, mas é o conhecimento dessas trajetórias o que mais pode contribuir para facilitar o acesso dos grupos tradicionalmente excluídos à escrita, via escola; ou seja, para proporcionar, por meio da escola, uma maior circulação pelas práticas letradas àqueles que provêm de famílias com tradiçáo de analfabetismo, geralmente os mais pobres, que vivem nas margens da ordem social, pouco usufruindo dos bens e serviços do estado. O exame dessas trajetórias é relevante para entender o papel da coletividade, da resistência, da subversão no processo de letramento desses grupos. Neste trabalho, apresentarei resultados de pesquisas do nosso grupo sobre esses letramentos - letramentos de resistência - em três grupos: comunidades quilombolas do sul do país (SITO, 2010); grupos de jovens ativistas negros do movimento do hip-hop na cidade de São Paulo (SOUZA, 2009) e 
alfabetizadores populares, sem diploma, ensinando adultos a ler e escrever na periferia da cidade de São Paulo (VÓVIO, 2008).

$\mathrm{O}$ interesse por esses grupos vai de encontro à perspectiva da escola, que tende a apoiar práticas de letramento dominantes, as de outras instituiçóes poderosas e influentes no tecido social, assim como ela própria. Letramentos locais, de resistência, adquiridos em trajetórias pessoais singulares, às margens da educação formal, que moldam a vida cotidiana das pessoas, são menos visíveis e recebem menor apoio. Resultados da pesquisa científico-acadêmica como os já mencionados poderiam ser interpretados como uma interpelação para o abandono dos modelos universais e autônomos de letramento, de acesso limitado e pressupostos elitistas, em favor da adoçáo de modelos locais. No entanto, um apelo dessa natureza não leva em consideração a história da instituição escolar e a natureza reflexivo-analítica de suas práticas, visando a objetivos socialmente valorizados. Mais do que tentar transformar a instituição, parece necessário sugerir práticas e atividades que de fato visem ao desenvolvimento do letramento do aluno, entendido como o conjunto de práticas sociais nas quais a escrita tem um papel relevante no processo de interpretação e compreensão dos textos orais ou escritos circulantes na vida social. O elemento-chave é a escrita para a vida social.

A descrição de práticas que propiciem o letramento na escola pode ser objeto relevante da pesquisa sobre o letramento, também com fins aplicados, relacionados ao favorecimento da inserção, na cultura letrada, dos grupos mais frágeis de nossa sociedade. Nessa linha, nosso grupo de pesquisa tem desenvolvido projetos de pesquisa-ação visando ao desenvolvimento de projetos de letramento (KLEIMAN, 2000; TINOCO, 2008; CUNHA, 2010), projetos de trabalho escolar que destacam a centralidade das práticas sociais de letramento no processo educacional e por isso tornam-no o eixo estruturante das atividades escolares, da apresentação dos conteúdos curriculares e do desenvolvimento de temas valorizados.

Neste trabalho, apresento, na primeira parte, consideraçóes sobre o letramento escolar e suas implicaçóes para o ensino e a pesquisa; nas segunda e terceira partes do trabalho, exponho os dois tipos de pesquisa brevemente apresentados anteriormente, os quais considero relevantes para desenvolver programas de ensino favoráveis aos alunos socialmente mais vulneráveis, ou seja, programas que intentem remover alguns dos obstáculos para o acesso ao mundo da escrita: primeiramente, as pesquisas sobre os projetos 
de letramento desenvolvidos pelo grupo e, em seguida, as pesquisas sobre letramentos locais, desenvolvidos fora da escola.

Em trabalho recente, Pardue (2010) destaca a importância das práticas culturais marginais, da margem em relação ao centro, para que antropólogos, arquitetos e geógrafos possam melhor "discutir o sentido da cidade como um fenômeno revelador da humanidade”. Eu adiciono educadores a esse grupo e apresento a contribuição a seguir para tal discussão.

\section{O letramento escolar}

O conceito de letramento está tendo um certo impacto no ensino da língua escrita na escola, daí que uma questão de destaque nesse contexto seja a das implicaçóes curriculares do letramento, tal qual inferidas por aqueles que atuam na esfera acadêmica, por um lado, e por aqueles que atuam nos anos iniciais do ensino fundamental - o primeiro ciclo - visando à alfabetização do aluno, por outro.

No contexto escolar incumbido da alfabetização dos alunos, no qual, aliás, o conceito do letramento parece ter tido maior influência, houve uma ressignificação bastante significativa em relação ao conceito que se originou no contexto acadêmico. A ressignificação à qual nos referimos é a que interpreta o letramento como uma nova metodologia de ensino da escrita, o que ocasionou o surgimento de uma falsa dicotomia: ou a criança é alfabetizada pelo método tradicional de alfabetização ou ela é letrada pelo "novo método" do letramento. Pode-se afirmar, utilizando o conceito de apreciação valorativa de Voloshinov/Bakhtin (1979), que houve um revozeamento do conceito no contexto educativo escolar, envolvendo a ressignificação do conceito de método, adquirindo assim sentidos valorados nessa esfera de atividades, que se preocupa intensivamente com a renovação metodológica a fim de atualizar de forma constante a sua ação didáticopedagógica. Essa valoração parece-nos uma resposta de resistência aos modos autoritários em que os discursos sobre como ensinar vêm sendo impostos aos que trabalham as escolas (por exemplo, via PCN).

Ora, reitero (cf. KLEIMAN, 2005) que não existe "método" de letramento, como conjunto de estratégias didáticas para o ensino inicial da leitura e da escritura. Há muitos modos - métodos, se forem sistemáticos de alfabetizar, e todos eles, simples ou complicados, modernos ou antigos, 
penosos ou prazerosos, fazem parte do conjunto de práticas escolares de letramento e são sócio-histórica e culturalmente situados. A alfabetização é uma prática de letramento que pode envolver diferentes estratégias (reconhecimento global da palavra, reconhecimento de sílabas, leitura em voz alta, leitura silenciosa), diversos gêneros (cartilhas, exercícios, imagens, notícias, relatos, contos, verbetes, famílias de palavras), diferentes tecnologias (lápis, caneta, papel, quadro negro, giz, lousa branca, pincel atômico, livro, tela e teclado).

As práticas que sustentam e mobilizam as diversas atividades, gêneros e suportes textuais na sala de aula são práticas discursivas ${ }^{1}$, que atualizam modos de falar, silenciar, perguntar, responder, refletir sobre o alfabeto, o texto, a língua escrita, a língua falada; sobre os motivos pelos quais se lê e se escreve; sobre as normas relativas aos objetos e modos de ler e escrever; sobre o que a escrita representa para diversos segmentos sociais e as características das representaçóes daí emergentes, situadas em tempos e espaços específicos. Enfim, tudo isso (e muito mais) é mobilizado e, de alguma forma atualizado, no trabalho de ensinar e aprender a ler e escrever, ou seja, nas práticas de letramento visando à alfabetizaçáo inicial do aluno.

$\mathrm{Na}$ esfera acadêmica, mantém-se que a adoção de uma concepção de letramento para ensinar acarreta uma compreensão ampla da língua escrita, de modo a incluir as práticas de ler e escrever da vida social. Isso teria, naturalmente, implicaçóes metodológicas e curriculares para a alfabetização e o ensino da língua escrita em geral. Entretanto, refuta-se a dicotomia alfabetizar versus "letrar" que está pressuposta em afirmaçôes como "deve-se letrar, não alfabetizar" ou "eu não estou alfabetizando, estou é letrando”.

Bunzen (2009) ataca uma perspectiva curricular do letramento que se limite a especificações didático-metodológicas, por mais importantes que elas sejam. Isto porque, nessa perspectiva, entre outras coisas, as práticas letradas são secundárias, uma vez que os esforços todos se concentram nos modos de ensinar; a perspectiva curricular, segundo Bunzen (op. cit., p. 127), "quase não leva em consideração como são ensinadas e construídas as relaçóes de poder, identidade, crenças e valores sobre a cultura escrita na escola."

Uma perspectiva escolar do ensino da língua escrita pode, no entanto, estar filiada a uma perspectiva sociocultural de letramento. Nesse caso, a abordagem antropológica, com observação etnográfica, própria dos estudos de letramento, é posta a serviço da observação, por parte do professor, das 
falas da turma, como se fosse uma pequena comunidade cujas práticas discursivas constituem o alvo do trabalho etnográfico do professor (HEATH, 1983). Também, nesse caso, o sistema da escrita, sob escrutínio e análise da turma para fins de apropriação, continua sendo objeto do trabalho escolar, porém sem necessariamente constituir-se em eixo estruturante do programa.

Uma perspectiva escolar de letramento - que, afirmo, não é contraditória a uma perspectiva social da escrita na esfera de atividades escolares - tem por foco atividades vinculadas a práticas em que a leitura e a escrita são ferramentas para agir socialmente. Aliás, as práticas escolares de aprendizagem e uso da língua escrita, ainda que "estritamente escolares", são também práticas sociais, sendo que muitas delas, como algumas que serão mencionadas na próxima seção, tomam por base práticas sociais e, portanto, recontextualizam as práticas com as quais os alunos convivem fora da escola, tornando-as mais significativas para eles.

A dificuldade de implementar, em atividades didáticas, uma concepção da escrita para a vida social reside no fato de ela ir de encontro à concepção tradicional de ensino da escrita, que, afinal de contas, reflete a história social e cultural da instituição escolar. Uma instituição que, nas palavras de Lahire (2001, p. 134), visa a transformar a relação da criança com sua própria linguagem, pois suas práticas permitem "tratar a linguagem como um objeto, dissecá-la, analisá-la, manipulá-la e fazer descobrir suas regras de estruturação interna em todos os sentidos possíveis". Tal finalidade opóe-se frontalmente à relação que a criança estabeleceu com a linguagem nas práticas sociais de que já participou, e que tornavam a língua um conhecido íntimo, “a roupa familiar", na metáfora de Voloshinov/Bakhtin (1979, p. 85), fazendo com que a criança pudesse, novamente segundo Lahire, "quase ignorar a sua [da linguagem] existência, de tal maneira que a sua presença era indissociável das situações, dos objetos designados, dos outros, das intençóes, das emoçóes, dos atos" (2001, p. 134).

A relação reflexivo-analítica com a língua começa com a alfabetização, prática durante a qual a criança é submetida a exercícios fonológicos e ortográficos que são produto de um trabalho de análise milenar, realizado pelos gramáticos do passado (v. LAHIRE, op. cit.). Estaria, então, sendo solicitado aos professores, na perspectiva escolar do letramento para a vida social, que transformassem a própria instituição, abandonando as atividades de análise da língua, que constituem, de fato, os primeiros passos na trajetória 
que leva para um distanciamento cada vez maior da prática linguageira cotidiana, tal qual exigido na produção de um ensaio ou uma dissertação? (GEE, 1996; LAHIRE, 2001; HEATH, 1983). Obviamente que não: não se pretende que a transformação de uma instituição originada há séculos, com a revolução industrial, e que tem resistido a muitas tentativas de reformas, faça parte do programa do alfabetizador.

Em contrapartida, como já vários autores vêm afirmando (BUNZEN, 2009; TINOCO, 2008; KLEIMAN, 2009), há desdobramentos da concepção social da escrita que não envolvem mudanças estruturais, que poderiam ser incorporados em um currículo escolar que visasse ao ensino da escrita relacionado a diversas esferas de atividade na vida social. Em outras palavras, é viável trazer os conteúdos considerados relevantes e analisá-los junto com os alunos, na linha da atividade analítica que sustenta a construção do conhecimento sobre a língua e linguagem, a partir da prática social. Segundo Kleiman $(2007$, p. 5), "a prática social como ponto de partida e de chegada implica, também, uma pergunta estruturante do planejamento das aulas diferente da tradicional, que está centrada nos conteúdos curriculares: "qual a seqüência mais adequada de apresentação dos conteúdos?”. Se a prática social é estruturante, continua a autora, a pergunta que orientaria o planejamento das atividades didáticas seria "de ordem sócio-histórica e cultural: quais os textos significativos para o aluno e sua comunidade"? É com base nessa pergunta que o currículo, visando à apropriação dos gêneros ${ }^{2}$, por exemplo, ou das combinaçóes ortográficas da língua, seria cumprido a contento.

Se aceitarmos que o letramento do aluno é a função primeira da escola, então é o letramento o princípio estruturador do currículo. O letramento é um conjunto de práticas discursivas que envolvem os usos da escrita (KLEIMAN, 1995); é fato que os discursos circulam em esferas da atividade humana e a escola é uma dessas esferas; segue-se, então, que, na esfera escolar, circulam práticas sócio-históricas e culturais próprias dessa esfera de atividade, que carregam em si, tal como outras práticas, a potencialidade de transformação e mudança, à medida que a interação sofre transformaçóes decorrentes de novas dinâmicas, novos atributos dos papéis sociais, novas tecnologias e ferramentas semióticas. Como bem aponta Bunzen (2009; p. 115-116), ao referir-se à dinâmica sócio-histórica das práticas discursivas na escola, as linguagens e instrumentos semióticos usados nas interaçóes na aula 
"apontam para facetas da dinâmica discursiva de sala de aula e da relação com a produção de sentido e de sistemas de referências, compreendidas como interpretaçôes possíveis que os grupos humanos organizam do mundo".

Note-se que são interpretações possíveis, não únicas, e sujeitas a mudanças em função da natureza das relaçóes sociais que se estabelecem em uma escola específica, em um tempo determinado. E, como em toda interação na aula, as transformaçóes podem transcender as paredes da sala de aula.

Podemos afirmar, em resumo, que na interpretação não dicotômica do conceito de letramento está reafirmada a essência da atividade de ensinar a ler e escrever: não se trata de aprender o alfabeto, mas o funcionamento da língua escrita, levando em conta a situação sócio-histórica e cultural do aluno, sua época, suas necessidades, as exigências da sociedade, os papéis que se espera possa desempenhar, os novos instrumentos e tecnologias que se deseja que saiba usar. A primeira e mais importante implicaçáo curricular ${ }^{3}$ dessa posição, em minha opinião, envolve a adoção de uma concepção social da escrita voltada para a prática de ler e escrever, que, nossos estudos e experiências mostram, ajuda a contextualizar os objetos de ensino, proporcionando um marco para atribuição de sentidos pelos alunos.

\section{Projetos de letramento: práticas sociais na escola}

A dificuldade inerente a uma abordagem social, em uma instituição cuja vocação é a atividade reflexivo-analítica, pode ser amenizada por meio dos projetos de letramento, que o nosso grupo de pesquisa tem estudado sistematicamente, inclusive por meio da pesquisa-ação no campo da formação de professores. (KLEIMAN, 2000; TINOCO, 2008; OLIVEIRA; 2008; CUNHA, 2010).

Diferentemente das progressóes curriculares voltadas para o ensino e desenvolvimento de um conteúdo, em um projeto de letramento há uma dinâmica ditada pela prática social, que faz com que determinado conteúdo do programa para o ciclo, ou o ano, seja ensinado em meio a um conjunto de diversos outros, em discursos que se organizam como em uma corrente enunciativa sem limites, exceto aqueles dados pela finalização do projeto e que contribuem para sua aprendizagem e concretização. Estabelece-se uma dinâmica diferente daquela em que o conteúdo-alvo do ensino constitui o 
elemento em torno do qual são estruturadas as unidades de ensino, sejam elas aulas, sequências, ou unidades do livro didático, entre outras possibilidades. Os projetos de letramento requerem um movimento pedagógico que vai da prática social para o "conteúdo" (seja ele uma informação sobre um tema, uma regra, uma estratégia ou procedimento), nunca o contrário (KLEIMAN, $2000 ; 2006)$. O projeto de letramento não substitui os eixos temáticos nem os eixos conteudísticos relevantes no trabalho escolar. Ele é um eixo estruturador das atividades em sala de aula, que permite ressignificar temas e conteúdos no contexto, em consequência de sua valoração pela turma.

Vejamos um exemplo, entre muitos outros observados ou relatados por professores (v. KLEIMAN, 2009). Relatando como começou um projeto que interessou e encantou uma turma de Educação Infantil durante quase um ano, a educadora da turma conta que o "projeto do milho" surgiu do interesse das crianças por um conto infantil que insistentemente pediam que fosse relido. No desenvolvimento do projeto, em que o milho foi plantado, colhido, moído, cozido, foi construída uma espessa rede de eventos de letramento em que circulavam textos e gêneros da escrita, como diagramas, fitas métricas, livrinhos, pastas, transparências, desenhos, sem que houvesse uma pré-definição dos conteúdos a serem abordados, como a professora da turma relata: "Enquanto o milho crescia, o projeto ia tomando forma”. Aliás, alguns dos gêneros introduzidos, como uma cronologia sobre a história das atividades empreendidas no projeto, diagramada na forma de uma linha do tempo, espontaneamente iniciado pelas crianças enquanto monitoravam o crescimento dos pés de milho, certamente náo podem ser considerados conteúdos normalmente incluídos num programa para crianças da pré-escola.

Temos, então, que em um projeto de letramento, o tema surge da observação por parte da professora do que interessava à turma (comparável, diríamos, à observação de cunho etnográfico, na grande maioria das pesquisas sobre o letramento); os objetivos e conteúdos são aqueles do currículo escolar; os planos de atividades visam ao letramento do aluno e, finalmente; a dinâmica de atividades - inclusive as analíticas de objetificação da língua para fins de reflexão - são determinadas pelo desenvolvimento do projeto, que pode assumir novos ritmos e caminhos em todo momento, segundo os interesses do aluno e da comunidade escolar. É importante ressaltar, no entanto, que a flexibilidade não é sinônimo de ausência de planejamento. 
Além do planejamento inicial, o ritmo do projeto exige um planejamento constante de atividades de aprendizagem. O professor que orienta um projeto de letramento não vai para a sala de aula observar e, acidentalmente, trabalhar as práticas cuja oportunidade aparece. Pelo contrário. Na turma de Educação Infantil, por exemplo, quando as crianças se interessavam, mesmo que fugidiamente, por algum aspecto do tema, a professora o retomava, nessa aula ou na aula seguinte, quando o considerava relevante para os objetivos educacionais. Tal retomada exigia pesquisa, elaboração de materiais, preparo de aulas de modo intensivo e constante.

Aparentemente mais complexa é a ressignificação do ensino da língua portuguesa no Ensino Fundamental e no Ensino Médio por meio de projetos de letramento (ver TINOCO, 2008; BALTAR, 2006; CUNHA, 2010), tanto pela organização desses segmentos do ensino, que desestimula a integração de conhecimentos e atividades, quanto pelo aumento de exigências e demandas programáticas e curriculares. Aliás, um incidente observado em uma reunião de formação de professores em serviço parece indicar que tal dificuldade é a norma na maioria das disciplinas. Nessa reunião, com professores de todas as disciplinas do Ensino Médio e Fundamental, visávamos à adesão dos professores aos projetos de letramento no coletivo escolar. Os professores pareciam ter algumas dificuldades em aceitar que a existência de algum objetivo significativo para ler e escrever poderia tornar até o ensino de conteúdos mais acessível ao aluno, quando uma professora de Geografia disse que ela entendia o que queríamos dizer. Todo ano - ela continuou -, odiava chegar às unidades sobre formação rochosa e geologia porque eram entediantes para os alunos e para ela também, mas recentemente fora convidada para participar de um grande projeto de elaboração de mapas utilizando o Sistema de Informações Geográficas e, no contexto desse projeto, um dos coordenadores, professor de Geologia, tinha dado uma aula maravilhosa sobre o uso das informaçóes geológicas na elaboração de cartas cartográficas. Isso, continuou a professora, tinha mudado absolutamente sua perspectiva sobre a matéria e, por esse motivo, não via a hora de chegar à anteriormente odiada unidade para poder ensinar a seus alunos as questóes de geologia agora sob o novo olhar. $\mathrm{O}$ exemplo ilustra como é difícil pensar na escola tradicional como um espaço em que a relevância seja definida pelo aluno e não pelo professor, um pré-requisito de todo projeto de ensino ${ }^{4}$, inclusive dos projetos de letramento. 
Não obstante as dificuldades, como em todo projeto com finalidades didático-pedagógicas, a integração disciplinar é altamente desejável e, nos contextos dos projetos de letramento, não só é possível como inevitável. Em uma descrição de uma experiência de elaboração de Jornal Escolar por turmas de $1^{\circ}$ e $2^{\circ}$ anos do Ensino Médio, Cunha (2010) relata ter havido uma dinamização do ensino de gêneros - o alvo era o artigo de opinião - objetivo que, inserido na corrente enunciativo-discursiva do projeto, adquiriu uma vitalidade e um dinamismo que são pouco comuns quando o eixo orientador do ensino é o gênero em si mesmo. Por se tratar de um projeto visando à elaboração e publicação de um jornal escolar, que empresta recursos das esferas de atividades jornalística ${ }^{5}$ e escolar, o gênero artigo de opinião, nesse projeto, passou por um processo de ensino sistematizado, próprio da esfera de atividades escolar (como nas sequências didáticas da abordagem de Dolz, Noverraz e Schneuwly (2004)), mas sua produção se deu concomitantemente a outros textos de outros gêneros, em decorrência da multiplicação de situações em que a escrita era necessária para posicionar-se em relação a uma questão real da vida escolar dos alunos. Multiplicaram-se, assim, os gêneros potencializadores da escrita, que foram mobilizados de modo autêntico e contextualizado, em tempos e espaços específicos dessa esfera de atividades.

Na elaboração do jornal, segundo relata Cunha (op.cit.), os estudantes fizeram uso de instrumentos mediadores (VIGOTSKY, 2003; RUSSELL, 1997), próprios dos sistemas de atividades envolvidos nas esferas jornalística e escolar: cadernos, livros (didáticos), quadro-negro, provas, aulas, gravadores, câmeras, transcrições, reportagens, softwares de impressão, computadores, Internet, dicionários. Para elaborar uma das reportagens sobre a proibição do namoro dentro do prédio escolar, realizaram debate da questão em sala de aula; gravaram entrevistas com a Diretora e com outros estudantes e professores, a fim de obter diversas versóes da polêmica em questão; transcreveram as entrevistas; pesquisaram outros casos que apontassem precedentes; compuseram um texto de reportagem; criaram manchetes; fotografaram e escreveram legenda; editaram os textos produzidos, fazendo algumas dessas etapas sucessivas vezes, até chegar à versão final da reportagem.

A produção dessas redes genéricas não é incomum em projetos de letramento. Voltando ao âmbito da Educação Infantil, em um projeto desenvolvido em uma turma de bebês de sete meses até um ano e meio de 
idade, a educadora responsável convidou as famílias dos nenês a registrar em um caderno um momento da vida do filho. Um dos objetivos era a elaboração de um livrinho - como registro e futuro material de leitura da criança, uma finalidade própria de uma instituição sustentada pelo mundo da escrita, procurando promover os primeiros contatos da criança com a cultura escrita. Outro objetivo, que pretendia conhecer melhor a criança e sua família, estava ligado à esfera de atividades do trabalho da educadora. E, ademais, o projeto contribuiu para o letramento da criança na esfera íntima, familiar, na medida em que os pais desses bebês se familiarizaram com funçóes arquivais em contextos íntimos e, ainda, com funçóes prazerosas, quase lúdicas da escrita, até então desconhecidas por eles, envolvidas, por exemplo, na observaçáo e registro de um momento da vida do filho, na customização do caderno do filho para diferenciá-lo dos demais, na exposição dos cadernos. As esferas de atividades do cotidiano familiar e as da escola se integraram numa rede constituída de atividades e gêneros híbridos (CUNHA, 2010), como acontece caracteristicamente na experimentação com gêneros na situação escolar.

Tinoco (2008) descreve uma reticulação semelhante nos projetos de letramento que desenvolveu na disciplina Estágio com seus alunos, professores atuantes na rede estadual de ensino no agreste do Rio Grande do Norte, em curso de Letras para a formação inicial de professores e sem formação específica ${ }^{6}$ e nos projetos que, por sua vez, esses professores atuantes e em processo de formação desenvolveram nas suas turmas de Ensino Fundamental e Médio. As turmas participaram do Concurso Nacional Tesouros do Brasil, que se destina à valorização de patrimônios brasileiros, e foi esse concurso que se transformou em projeto de letramento desses estagiários.

As práticas de letramento, segundo relata Tinoco (op. cit.) esteada na sua análise em uma concepção bakhtiniana da linguagem, começaram pela leitura do regulamento e da ficha de inscrição, seguida de um debate, com perguntas, releituras e respostas, e, em alguns casos, encaminhamento por escrito de algumas perguntas para o site do concurso. As respostas da coordenação do concurso, pelo correio eletrônico, constituíram mais uma atividade de leitura e debate. A necessidade de preenchimento eletrônico das fichas de inscrição desencadeou outras atividades, para se familiarizar com a tecnologia e o gênero. Após o envio eletrônico das inscriçôes, a coordenação 
do concurso enviou material didático com sugestôes de procedimentos, tais como, estratégias de identificação do patrimônio e de levantamento de dados em documentos dos mais variados gêneros: livros, jornais, cartas pessoais, entrevistas.

Ademais, desse conjunto de atividades e gêneros da esfera jornalística e de atividades próprias de competiçóes e enfrentamentos, viabilizados por meio de gêneros das novas tecnologias da informação e comunicação, a corrente de gêneros e discursos propiciada pelo concurso foi enriquecida com gêneros da esfera de atividade escolar. E, nesse contexto, em se tratando de um conjunto de novas atividades visando a concretizar os objetivos de um projeto, ocorreram experimentaçóes que nunca antes haviam sido realizadas pelos professores, segundo nos conta Tinoco. Após a elaboraçáo do anteprojeto e do projeto para o concurso, os professores organizaram suas turmas para a realização das atividades planejadas.

Apresento um exemplo dentre os vários descritos por Tinoco (op. cit.): com a turma que escolheu o rio que atravessava a cidade como patrimônio a ser tematizado, surgiu a aula-passeio, que requeria que os alunos solicitassem autorização da direção para sair da escola e requisição de ônibus à Prefeitura, que elaborassem os objetivos da aula-passeio e dividissem as tarefas a serem realizadas, tais como registros fotográficos e descrições das atividades observadas. $\mathrm{O}$ passeio instigou outras atividades de caráter político-ambiental, como debates sobre a importância de uma campanha de preservação do rio; elaboração de placas de advertência, folhetos informativos e panfletos sobre a necessidade de preservar o rio; produção coletiva de um relatório sobre o passeio, tudo isso antes da produção da versão final do relatório, a ser enviado ao Concurso Nacional.

O projeto de letramento parece constituir um meio de dinamização da aula, pois a reflexividade e abstraçáo passam a formar parte do arsenal de instrumentos do aluno para dar conta das tarefas nessa rede de atividades, que integra tanto as práticas de letramento da esfera escolar quanto as práticas de outras esferas que o desenvolvimento do projeto demanda. Nesse percurso, as práticas sociais náo escolares passam a ter existência no processo de ensino-aprendizagem. Daí a relevância atribuída a essa linha de pesquisa e ação no grupo Letramento do Professor. 


\section{O contraponto dos letramentos locais}

Por letramentos locais entendo as práticas de letramento vernáculas, náo institucionalizadas, menos prestigiosas e menos visíveis que as práticas de letramento da escola, da universidade, da imprensa, entre outras instituiçóes, que são práticas legitimadas globalmente (cf. BARTON; HAMILTON, 2000).

Assim como as práticas não escolares de letramento são relevantes para o ensino da escrita no contexto dos projetos de letramento, também a investigação de práticas locais, igualmente não escolares, é relevante para melhor entender a problemática de ensino da língua escrita a grandes parcelas da população brasileira, particularmente àqueles alunos que provêm de famílias com pouca ou nenhuma escolaridade e de classe social mais pobre.

No Brasil, o acesso a práticas legitimadas de uso da escrita - aquelas que a escola visa a ensinar - não é garantido pela escolarização, constituindo-se em mais uma barreira para acesso e mobilidade social de muitos. Assim, o letramento, geralmente o escolar, contribui para que as relaçóes de poder já instituídas sejam preservadas, para que os letramentos dos grupos poderosos (os letramentos dominantes, na terminologia de Barton e Hamilton (2000)) sejam legitimados. Nesse contexto social, o letramento dos destituídos do poder, dos mais pobres, dos que vêm de famílias sem escolaridade, equivale a um processo de aculturaçáo via escrita e configura-se como um processo identitário, de dificuldade e complexidade extremas (KLEIMAN, 1998).

$\mathrm{Na}$ Antropologia e nos Estudos Culturais, a identidade é mutável, flexível, fluida, instável e fragmentada (HALL, 2000). Também é situada, pois, na interaçáo com o outro, ocorrem processos de identificação e diferenciaçáa, que a transformam constantemente. $O$ processo de construçáo identitária na interaçấo não é um processo tranquilo, de coexistência multicultural, mas de conflito e contradição, no qual as identidades estão em constante construção e mudança.

Os processos que contribuem para as construçôes identitárias são discursivos. Para além das identidades nacionais, étnicas, de gênero, são construídas discursivamente identidades profissionais, como as de professor, médico, advogado; identidades reguladoras e avaliativas, como as que classificam e dividem uma turma em alunos bons ou ruins; com ou sem 'futuro'; bons meninos e delinquentes. $\mathrm{O}$ processo acontece diuturnamente 
em instituiçóes formadoras, como a escola, as faculdades, enfim, nos espaços onde se ensina aos alunos a falar e pensar como os membros do grupo social, ou profissional, a que aspiram pertencer. Nesse processo, a interação é determinante, pois permite que os participantes se posicionem e sejam posicionados pelo outro segundo relaçóes de poder, status, hierarquia, gênero, etnia. Esses posicionamentos discursivos, por trás das mutáveis construções identitárias, fornecem orientações momentâneas, locais, circunstanciais, passo a passo, sobre o status, poder e legitimidade dos participantes da interação, dentro dos parâmetros que a instituição permite (HOLLAND et al., 1998; KLEIMAN, 2006).

Analisando práticas de líderes de movimentos populares, Kleiman (1998) aponta os conflitos daqueles que presenciam constantemente os abusos de poder infringidos por meio da escrita, mas que devem, ao mesmo tempo, aderir a essas práticas, na interação, em função das posições sociais que ocupam como líderes e representantes de seus grupos. A manutenção dos valores do próprio grupo é uma estratégia comumente usada para garantir sua legitimidade nos dois grupos, sem identificar-se ou ser identificado com grupos alheios aos interesses de suas comunidades de origem.

A investigação de lideranças de movimentos sociais e de suas práticas de letramento, envolvendo a análise crítica de situações locais, nas quais o uso da escrita é contextualizado em função das identidades e objetivos dos usuários da escrita e seus contextos específicos, tem sido frequente nas pesquisas de nosso grupo - Letramento do professor - com o objetivo de conhecer e tornar visíveis as trajetórias de letramento desses sujeitos, os modos pelos quais eles construíram suas identidades de leitores, escritores, educadores em contextos não escolares. São constataçóes desses estudos a complexidade e pluralidade das práticas de letramento desses grupos e a variedade de interaçóes e eventos de letramento nos seus processos de apropriação dos usos da escrita.

Nessa linha de investigação, Sito (2010) pesquisou as práticas de letramento de uma comunidade quilombola denominada Casca, no estado do Rio Grande do Sul, em processo de legitimação da posse de terras, no marco das atuais políticas afirmativas e multiculturais governamentais. Nesse processo regulatório, estavam em confronto as práticas tradicionais da comunidade quilombola e aquelas impostas pelo Estado para as negociaçóes entre seus representantes e as lideranças quilombolas. Sito mostra como as 
práticas de letramento tradicionais do grupo estão vinculadas a formas de pensar, agir e valorizar (inclusive a autovalorizaçáo) e como os membros da comunidade apropriam-se de práticas legitimadas, ressignificando suas identidades no processo.

O estudo de Sito (2010) mostra que o contato com as instituiçóes públicas desencadeou, no seio da comunidade, um processo de construção de identidade quilombola, imbricada nas práticas tradicionais de letramento do grupo, em concorrência com as práticas dominantes, e que "as práticas de letramento das lideranças quilombolas se mostraram em valor desigual, com menos prestígio, do que as práticas de grupos hegemônicos e legitimadas pelo Estado" (op. cit., p. 50). Nas descriçóes realizadas pela pesquisadora, fica evidente que a desigualdade tende a acentuar os conflitos entre a instituição de maior poder - o INCRA, no caso, mas poderia muito bem ser a escola - quando nada é feito para diminuir ou atenuar as diferenças e a dominância e visibilidade das práticas legitimadas das instituições públicas vis a vis as práticas tradicionais. A pesquisa também mostra de modo muito claro os empecilhos criados pelo próprio Estado, que exige a existência de entidades e o uso de gêneros que circulam em instituiçóes letradas por esses grupos desconhecedores das práticas letradas de prestígio, para o acesso ao processo de regularização do território. Não obstante essa tensão, decorrente de exigências como a constituição de uma Associação Comunitária na comunidade, o registro das atividades comunitárias em atas, a elaboração de projetos, a prestação de contas; o processo constituiu-se em ambiente para a emergência de novos gêneros e eventos de letramento, ao mesmo tempo em que se consolidava a pertinência dos eventos locais de uso da escrita, em outras palavras, das práticas tradicionais, como a guarda do testamento que lhes concedera posse das terras um século antes, ou as anotaçóes que registravam transaçóes comerciais em caderninhos pessoais. Em resumo, Sito constata a necessidade de examinar as questóes identitárias por causa da relação imbricada entre o letramento do grupo e o processo de constituição de identidade quilombola, no contato com o poder público: "as histórias inscritas e escritas em Casca constituíram usos sociais da escrita utilizados pela comunidade no processo de apropriação do tornar-se quilombola" e mostra ainda como os constantes movimentos para posicionar subalternamente as lideranças quilombolas por parte dos representantes do poder público produzem uma situação "que culmina em 
um conflito entre os valores dos diferentes atores que se chocam nessa arena" (SITO, 2010, p. 92-93).

Outro objeto de investigação relativo no campo das práticas não escolares de letramento consiste no estudo das trajetórias singulares de agentes de letramento formados em espaços outros que os das instituiçóes tradicionais de ensino superior ou do magistério, como as alfabetizadoras populares (VÓVIO, 2008) e os jovens ativistas no movimento hip-hop (SOUZA, 2009). Os sentidos que esses sujeitos atribuem a suas trajetórias e práticas de letramento e o impacto destas nas suas identidades de agentes de letramento, segundo mostram essas pesquisas, não deixam dúvidas sobre sua pertinência para as instituiçóes com finalidades educacionais e formativas.

O estudo de Souza (2009) argumenta que foi a apropriação da escrita o que permitiu aos participantes da pesquisa, jovens ativistas no movimento do hip-hop, redimensionar suas identidades como negros, moradores de periferia e ativistas, ressignificando seus papéis sociais. Os jovens participantes da pesquisa foram aos poucos ampliando seu raio de açóes, passando da contestação por meio de música e fala engajada, ao trabalho de educação e de formação em contextos educativos. Nesse processo, eles resistiam a modelos que os tinham excluído do espaço escolar e usaram a fluidez da expressividade cultural do hip-hop para se tornarem agentes de letramento que falam a língua de alunos vindos das margens da cidade - sem empregos, sem espaços de lazer, sem cuidados por parte do Estado- e continuam nas margens do sistema escolar.

Foi no seio das práticas culturais do movimento hip-hop e no decorrer dos densos debates, que a pesquisa de Souza propiciou o espaço em que os jovens do grupo Hip-hop Educando encontraram os modos de falar e escrever e os acervos de leitura que usaram nas suas atividades com fins educativos, de relevância para membros de suas comunidades de origem. Fizeram parte desse acervo de materiais com fins educativos, capa de CD, fanzine, rap, grafite, assim como produçóes coletivas de organização de eventos. Ao mesmo tempo, eles iniciavam, cautelosamente a princípio e com plena autoridade mais tarde, a participação em seminários e palestras sobre relaçóes raciais e discriminação, baseados na leitura de textos sobre a história da população negra no Brasil, em contextos escolares e universitários. A composição de rap, a elaboração dos fanzines, os eventos coletivos não apenas "causavam" 
- como também tornavam o manejo da língua oral e escrita um poderoso instrumento formador nas escolas e faculdades que os jovens visitavam (ainda às margens dos esforços educacionais do centro, é claro), pois eles imprimiam a resistência do movimento a práticas letradas escolares que por um lado valorizavam, e por outro refutavam, reformulando-as nesse processo. Souza caracteriza as práticas dos jovens ativistas como práticas de 'reexistência', pois elas não apenas resistiam ao modelo cultural legitimado, como também permitiam integrar e ressignificar as práticas relacionadas a outras esferas de atividades do cotidiano, de duração provisória, nos espaços moventes da rua, em que geralmente atuavam.

Assumindo também um conceito de identidade, produzido no contínuo intercâmbio de significações atribuídas aos eventos e às posições de sujeito negociadas na interação, Vóvio (2008) investiga as identidades leitoras e as trajetórias singulares de formação de educadores cujas experiências de escolarização formal são poucas e aparentemente de pouca pertinência nos seus processos de formação de leitores e alfabetizadores de jovens e adultos. Segundo Vóvio (op. cit. p. 2; p. 9), os sujeitos são educadores sem formação específica, que participam de um complexo processo de profissionalização de educadores de jovens e adultos, um território não formalmente reconhecido, no qual atuam profissionais diversos, com diversos níveis de escolaridade e formação. A modalidade em que atuam (EJA), destinada àqueles que não cursaram ou completaram a Educação Básica, abrange, ainda, segundo Vóvio, um enorme e heterogêneo grupo de pessoas afetadas pela sua condição de analfabetos, que os limita social e economicamente.

A análise de Vóvio mostra novamente o papel do letramento na construção identitária, na interação entre alfabetizadores e pesquisadora - também formadora deles - nas rodas de leitura promovidas durante a pesquisa. Os educadores mostram um grau de reflexividade incomum em relação tanto à natureza de suas identidades leitoras, como aos lugares que ocupam nas interaçóes e às relaçóes que estabelecem entre esses lugares, "configurações locais, relacionadas aos status e lugares que ocupam na situação, como outras mais amplas relacionadas a configuraçóes culturais, profissionais e societárias" (op. cit., p. 245).

$\mathrm{Na}$ reconstituição das histórias pessoais desses alfabetizadores e nas situaçóes de interação, destaca-se o fato de esses educadores se apresentarem como leitores competentes, capazes de ensinar a ler e escrever, de formar 
outros leitores e de interessá-los na leitura. Não são os cursos formais profissionalizantes os que propiciam essas construçóes, pois eles não têm diplomas nem certificaçóes, mas os próprios espaços de atuação comunitária que os autorizam a atuar como educadores e no qual constituem suas bem sucedidas relaçóes com a leitura.

Diferentes são as construções de alfabetizadoras atuantes na rede oficial do ensino, que hesitam em admitir seus gostos e objetos de leitura ou em validar suas práticas letradas fora do âmbito escolar, como mostra Kleiman (2006) ao cotejar os discursos identitários (que leitora sou eu?) de participantes da pesquisa de Vóvio e de alfabetizadores atuantes na rede estadual de ensino no interior de São Paulo, em programa de formação inicial do curso de Pedagogia, em uma universidade pública do estado de São Paulo. Essas alfabetizadoras, também experientes, desta vez na alfabetização escolar, parecem assumir as críticas da mídia e dos acadêmicos, quando questionam sua pertença plena nos grupos letrados. Enquanto os educadores populares se posicionam como leitores legítimos e constroem elos discursivos de solidariedade entre eles, as professoras assumem, nas interaçóes, as posiçóes subalternas que experienciam cotidianamente em relação aos seus professores universitários, à mídia, à administração escolar, não se apresentando como leitoras ou como membros legítimos dos grupos letrados que representam na escola.

\section{Considerações finais}

Duas práticas de pesquisa têm se mostrado relevantes nos nossos estudos sobre o letramento: em primeiro lugar, o exame de contextos educativos que reproduzem situaçóes de uso da escrita na vida social, os projetos de letramento; em segundo lugar, a identificação de práticas de letramento locais e das trajetórias singulares de lideranças e agentes de letramento atuando em situaçóes locais, às margens das práticas globais promovidas pelas instituiçóes educativas legitimadas, como a escola e a universidade.

A grande diversidade de significaçóes subjacentes aos letramentos dos grupos estudados, nas pesquisas aqui resenhadas, ajuda a compreender o dinamismo e a riqueza cultural dos eventos de letramento que promovem 
o sucesso que esses sujeitos atingem em sua inserção na cultura letrada, seja como novos usuários, no caso da comunidade quilombola de Casca, ou como agentes comunitários de letramento, como no caso dos jovens ativistas do movimento hip-hop e dos alfabetizadores populares, cujos letramentos constituem práticas efetivas de resistência.

Essas pesquisas nos mostram a necessidade de ruptura com os pressupostos do currículo tradicional a fim de promover, também na escola, experiências de acesso, circulação e dinamização das práticas de letramento para a vida social, experiências híbridas quanto aos valores locais e aqueles universais valorizados e legitimados pela escola.

A ausência de recursos econômicos que ainda perpassa o ensino público cria condiçóes de desigualdade de acesso à cultura letrada. Há outros obstáculos a esse acesso, decorrentes de enfoques que não levam em conta a heterogeneidade de experiências dos alunos. Os estudos do letramento nos permitem observar outros modos de acesso e distribuição dos bens culturais, de trajetórias de formação, de inserção nas práticas culturais hegemônicas, que culminam na apropriação das práticas de letramento que interessam ao grupo, na equalização das oportunidades de acesso a essa cultura, na autoafirmação e autorização dos sujeitos que seguem essas trajetórias singulares de letramento. Os projetos de letramento foram apresentados, nesse contexto, como ponto de partida para formular experiências de letramento escolar que favoreçam os alunos mais frágeis, do ponto de vista social e econômico, e diminuam as dificuldades e tensóes no processo de acesso aos universos da escrita.

\section{Notas}

1 Ou seja, elas produzem discursos sobre a escrita, filiados a algum conjunto de crenças, saberes, atitudes sobre determinado assunto (CHARAUDEAU; MAINGUENEAU, 2004. p. 168-176).

2 Em Kleiman (2006), apresento dados que mostram que a escolha do gênero como conteúdo relevante para o ensino não significa que o gênero deva constituir-se no elemento estruturante das práticas sociais mobilizadas no projeto, sob o risco de reduzir o objeto de ensino e o trabalho escolar aos seus aspectos formais e analíticos. 
3 Algumas delas têm sido discutidas e até incorporadas em programas de trabalho oficial (KLEIMAN, 2007; SECRETARIA MUNICIPAL DE CAMPINAS, 2008).

4 Os projetos pedagógicos, tais como os projetos de letramento de que vimos falando, ou os projetos de trabalho de Hernandez e Ventura (1998), entre outros, remontam aos projetos desenvolvidos no início de século por Dewey (1998) e seus seguidores.

5 A autora se apoia em Russell (1997), que propóe uma teoria de Atividades que se sustenta na Teoria de Sistemas de Gêneros, de Bazerman (1994), e na Teoria de Atividades, de Leontiev (1981).

6 O curso fazia parte do Programa para a Qualificação Profissional para a Educação Básica, vinculado à Universidade Federal do Rio Grande do Norte (UFRN). No trabalho, que descreve o conjunto de atividades desenvolvido pelos professores e seus alunos, Tinoco (2008) teoriza sobre os projetos de letramento.

7 Segundo Souza (2009), no contexto do ativismo dos jovens do hiphop, "causar" significa se fazer notar, dar destaque a fato, evento ou pessoa.

\section{REFERÊNCIAS}

BALTAR, Marcos. Competência discursiva e gêneros textuais: uma experiência com o jornal de sala de aula. Caxias do Sul, RS: Educs, 2006. BARTON, David; HAMILTON, Mary. Literacy practices. In: BARTON, David; HAMILTON, Mary; IVANIC, Roz (Org.). Situated literacies. London: Routledge, 2000, p. 7-15.

BAZERMAN, C. Systems of genres and the enactment of social intentions. In: FREEDMAN, A.; MEDWAY (Org.). Genre and the new rhetoric. London: Taylor e Francis, 1994, p. 79-101.

BUNZEN, Clecio. Dinâmicas discursivas na aula de português: o uso do livro didático e projetos didáticos autorais. 2009. Tese (Doutorado em Linguística Aplicada) - Instituto de Estudos da Linguagem, Universidade Estadual de Campinas, Campinas. 
CHARAUDEAU, Patrick; MAINGUENEAU, Dominique. Dicionário de Análise do discurso. São Paulo: Editora Contexto, 2004.

CUNHA, Rosana. Jornal Escolar: raio de ações, rede de significações. Reconfiguração do ensino de língua materna e dinamização da formação continuada do professor. 2010. Tese (Doutorado em Linguística Aplicada) - Instituto de Estudos da Linguagem, Universidade Estadual de Campinas, Campinas.

DEWEY, John. Experience and Education. New York: Simon and Schuster. A Touchstone Book, 1998 [1938].

DOLZ, J.; NOVERRAZ, M.; SCHNEUWLY, B. Sequências didáticas para o oral e a escrita: apresentação de um procedimento. In: SCHNEUWLY, B.; DOLZ, J. Gêneros orais e escritos na escola. Campinas: Mercado de Letras, 2004.

GEE, J. P. Social linguistics and literacies. Ideology in discourses. New York: Falmer Press, 1996.

HALL, Stuart. A identidade cultural na pós-modernidade. Rio de Janeiro: DP\&A Editora, 2003.

HEATH, S. B. Ways with words. New York: Cambridge University Press, 1983.

HERNÁNDEZ, F; VENTURA, M. A organização do currículo por projetos de trabalho. Porto Alegre: Artes Médicas, 1998.

HOLLAND, D.; LACHICOTTE JR., W.; SKINNER, D.; CAIN, C. Identity and agency in cultural worlds. Cambridge, Mass: Harvard University Press, 1998.

KLEIMAN, Angela B. Modelos de letramento e as práticas de alfabetização na escola. In: KLEIMAN, Angela B. (Org.). Os Significados do Letramento. Campinas: Mercado de Letras, 1995; p. 15-61.

. Schooling, Literacy and Social Change: Elements for a critical approach to the study of literacy. In: OLIVEIRA, M. K.; VALSINER, J. (Org.) Literacy in Human Development. London: Ablex Publications, 1998; p. 183-225.

KLEIMAN, Angela B. O processo de aculturação pela escrita: ensino da forma ou aprendizagem da função? In: KLEIMAN, A. B.; SIGNORINI, 
I. (Org.) O ensino e a formação do professor. Alfabetização de jovens e adultos. Porto Alegre: Artmed, 2000; p. 223-243.

. Preciso "ensinar" o letramento? Não basta ensinar a ler e escrever? Coleção Linguagem e Letramento em Foco, UNICAMP: Cefiel; MEC: Secretaria de Ensino Fundamental, 2005.

. Processos identitários na formação profissional: o professor como agente de letramento. In: CORRÊA, M. (Org.). Ensino de Lingua: Letramento e Representaçóes, Campinas: Mercado de Letras, 2006.

. Letramento e suas implicaçóes para o ensino de língua materna. Revista Signo, Santa Cruz do Sul, v. 32 n. 53, p. 1-25, dez. 2007

. Projetos de letramento na educação infantil. Revista Caminhos em Linguística Aplicada, v. 1, n. 1, 2009. Disponível em: <www.unitau.br/ caminhosla>. Acesso em: 29 jun. 2010, p. 1-10.

LAHIRE, Bernard. O Homem Plural. As molas da Acção. Lisboa: Instituto Piaget, 2001.

LEONTIEV, A. N. Problems of the development of the mind. Moscow: Progress, 1981.

OLIVEIRA, Maria do Socorro. Projetos: uma prática de letramento no cotidiano do professor de língua materna. In: OLIVEIRA, Maria do Socorro; KLEIMAN, Angela B. (Org.). Letramentos múltiplos: agentes, práticas, representaçôes. Natal: EDUFRN, 2008, p. 93-118.

PARDUE, Derek . Uma Perspetiva Marginal. Abril, 2010, MS, 28 p. PREFEITURA DE CAMPINAS. Diretrizes Curriculares para o trabalho pedagógico com leitura e escrita na Educação Infantil. Campinas: Secretaria da Educação; Departamento Pedagógico, 2008.

RUSSELL, D. Rethinking genre in school and society: An activity theory analysis. Written Communication, 14(4), p. 504-554, 1997.

SITO, Luanda Rejane Soares. Ali está a palavra deles. Um estudo sobre práticas de letramento em uma comunidade quilombola do litoral do Rio Grande do Sul. 2010. Dissertação (Mestrado em Linguística Aplicada) Instituto de Estudos da Linguagem, Universidade Estadual de Campinas, Campinas. 
SOUZA, Ana Lúcia Silva. Letramentos de Reexistência: culturas e identidades no movimento hip-hop. 2009. Tese (Doutorado em Linguística Aplicada) - Instituto de Estudos da Linguagem, Universidade Estadual de Campinas, Campinas.

STREET, B. Literacy in theory and practice. Cambridge: Cambridge University Press, 1984.

TINOCO, Glícia M. Azevedo de M. Projetos de Letramento: ação e formação de professores de língua materna. 2008. Tese (Doutorado em Linguística Aplicada) - Instituto de Estudos da Linguagem, Universidade Estadual de Campinas, Campinas.

VIGOTSKI, L. S. Pensamento e Linguagem. São Paulo: Martins Fontes, 2003.

VOLOSHINOV, V.N.; BAKHTIN, M. M.; VOLOCHINOV, V. N. Marxismo e filosofia da linguagem. São Paulo: Hucitec, 1979 [1929]. VÓVIO, Cláudia Lemos. Entre discursos. Representações, práticas e identidades leitoras de alfabetizadores de pessoas jovens e adultas. 2007. Tese (Doutorado em Linguística Aplicada) - Instituto de Estudos da Linguagem, Universidade Estadual de Campinas, Campinas. 


\section{Access paths to the world of writing: importance of non-school literacy practices to scholar literacy}

\begin{abstract}
Based on social and historical conception of literacy rather than an instrumental one (STREET, 1984, KLEIMAN, 1995), this paper discusses aspects of school literacy, pointing out some of its implications for teaching and research. We present two lines of studies developed by the research group "Teacher Literacy": one focusing on the development, analysis and documentation of 'literacy projects' and its effects on school literacy; the other focusing local, vernacular literacies and on their effect on the identities of community leaders and agents. Both lines of research aim to contribute towards the development of teaching programs favoring students who are more vulnerable, from a social point of view, and whose access to the world of writing encounters many obstacles.
\end{abstract}

Keywords: Teaching project. Literacy culture.

\section{Trayectorias de acceso al mundo de la escrita: la importancia de las prácticas no escolares de literacidad para la literacidad escolar}

\section{Resumen}

Utilizando como referencial teórico una concepción social y histórica de los usos de la lengua escrita, opuesta a una concepción instrumental (STREET, 1984, KLEIMAN, 1995), este trabajo discute aspectos de la literacidad escolar y apunta algunas de las implicaciones de esa concepción para la enseñanza y la investigación. Son presentadas dos líneas de investigación desarrolladas por el Grupo de pesquisa "Literacidad del Profesor" - una que focaliza el desarrollo, análisis y documentación de "proyectos de literacidad" y sus efectos en el aprendizaje de la lengua escrita, y otra que investiga los usos locales, vernáculos, de la lengua escrita y su impacto en la identidad de líderes y agentes comunitarios. Ambas líneas objetivan contribuir para el desarrollo de programas de enseñanza favorables a los estudiantes más vulnerables del punto de vista social, cuyo acceso a la cultura escrita encuentra múltiples obstáculos.

Palabras clave: Proyecto escolar. Cultura escrita. 


\section{Angela B. Kleiman}

Departamento de Linguística Aplicada. Caixa Postal 6041. Instituto de Estudos da Linguagem, Unicamp. www.iel/unicamp.br/letramentodoprofessor E-mail: kleiman@mpc.com.br

Recebido em: $1 / 7 / 2010$

Aprovado em: 10/11/2010 